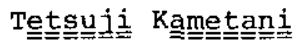 \\ Pharmaceutical Institute, Tohoku University, Aobayama, Sendai \\ 980, Japan
}

On October 1, 1914, Hamao Unezawa was born as the second son of Dr. Junichi Umezawa, a director of a principal hospital in historically cultural city of obama. He served to enrich science with a distinction and brilliance well worthy of upholding four generations of life scientists in the Umezawa family. Being a father of two sons already engaged in the scientific field, Hamao Umezawa has assured further continuity of the Umezawa tradition.

Hamao Umezawa graduated from Medical School, University of Tokyo, in 1937, and started his studies of microbiology and biochemistry in the Department of bacteriology, University of Tokyo. There he engaged in the study, of Japanese encephlities virus and immunochemistry. In 1944, he became the assistant professor of the Institute of Infectious Diseases (present name: Institute for Medical Sciences), University of Tokyo, and undertook the study of antibiotics. With the request of the Japanese government, he first studied processes for penicillin production and later for streptomycin, and began the research of new antibiotics in 1945. Also in 1945, he received Ph.D., Doctor of Medicinal Science at the University of Tokyo. When the National Institute of Health, Japan, was established in 1947, he became the director of the Department of Antibiotics. Since this time, he has devoted himself to the study of antibiotics and other bioactive microbial products. At the Department of Antibiotics of the National Institute of Health, Japan, he discovered kanamycin in 1957. Based on the royalties accrued on kanamycin, the Institute of Microbial Chemistry was founded in 1962 and Prof. Umezawa was appointed director in charge of all research there. From 1954-1975, he has been the professor of the University of Tokyo, directing research at the Institute of Applied Microbiology (1954-1965), and at the Cancer Biology Department of the Institute for Medicinal Sciences (1972-1975). In 1975, he retired from the post of professor of the University of Tokyo and in 1978 from the Director of Department 
of Antibiotics of the National Institute of Japan. Presently, he still continues to be the director of the prestigous Institute of Microbial Chemistry, and it is the headquarters of Japan's still very active antibiotic research efforts. With his firm medical roots, Prof. Hamao Umezawa has accomplished far more than expected of a man in a single lifespan. He has been awarded all the highest prizes in Japan due to his enormous contributions to the study of antibiotics and other bioactive microbial products. Through his research, he has gained worldwide acclaim and has been associated with academic memberships, honorary doctorates, honorary memberships, and memberships of scientific associations from across the globe as seen in the following lists. He has pioneered new research areas in the field of antibiotics, and always with challenging philosophy, and thereby discovered about 30 antitumor antibiotics, about 70 antimicrobial antibiotics, about 20 derivatives of animoglycosidic antibiotics, and 40 enzyme inhibitors as described later.

AWARDS

Order of Culture (Bunka-Kunsho) conferred by the Emperor of Japan (1962); Japan Academy prize for studies on kanamycin (1962); Princess Takamatsu Cancer Research Prize (1976); Asahi Prize for studies on kanamycin and other new antibiotics (1959); Prize from the Minister of the Ministry of Science of Japan (1959); Commandeur de l'ordre de la santé publique from France for studies on kanamycin (1960); Fujiwara Prize from the Fujiwara Foundation for pioneering study of new research fields in antibiotics and discoveries of new useful microbial compounds (1971); Prize from the Minister of the Ministry of Agriculture of Japan (1975); The Windsor C. Cutting Lectureship Award (University of Hawaii, U.S.A.) (1977); Karle-August Forster Prize, Mainz Academy, Germany (1977)

\section{HONORARY DOCTORATES}

Professor Emeritus of University of Tokyo (1977-); Doctor Honoris Causa, Faculty of Pharmacy, University of Santiago de Compostella, Spain (1977- ); Honorary Doctor of Medicine (Medicine Heders-Doktor), Royal Karolinska Institute, Sweden $(1978-)$

\section{OTHER APPOINTMENTS}

Member of Japan Academy (1969- ); Mitglied der Deutsche Akademie der Naturforscher 
Leopordina (1973-); Member of American Academy of Arts and Sciences, Boston, Massachusetts (1978-); Foreign Member of Royal Swedish Academy, Sweden (1978- ); Honorary Member of Japanese Association of Medical Sciences (1963-); Honorary Member of Brazil Cancer Society (1969-); Honorary Member of Poland Medical Association (1970- ); Honorary Member of Pharmaceutical Society of Japan (1974-); Honorary Member of International Chemotherapy Association (1977-); American Chemical Society; American Society for Microbiology; Biochemistry Society of Japan (Councillor); International Chemotherapy Association (Vice President, 1964-1967, and 1969-1975; President, 1967-1969); Chemical Society (London) (Fellow, 1963); Japan Antibiotic Research Association (President, 1971-); Japan Bacteriology Society (Councillor); Japanese Cancer Association (Director, 1966- ; President, 1978); Japan Chemotherapy Society (Director); New York Academy of Sciences (Fellow, 1955-); Member of U.S.A.-Japan Cancer Committee (1972-) 